\title{
Occupational exposure and amyotrophic lateral sclerosis in a prospective cohort
}

Citation for published version (APA):

Koeman, T., Slottje, P., Schouten, L. J., Peters, S., Huss, A., Veldink, J. H., Kromhout, H., van den Brandt, P. A., \& Vermeulen, R. (2017). Occupational exposure and amyotrophic lateral sclerosis in a prospective cohort. Occupational and Environmental Medicine, 74(8), 578-585.

https://doi.org/10.1136/oemed-2016-103780

Document status and date:

Published: 01/08/2017

DOI:

10.1136/oemed-2016-103780

Document Version:

Publisher's PDF, also known as Version of record

Document license:

Taverne

Please check the document version of this publication:

- A submitted manuscript is the version of the article upon submission and before peer-review. There can be important differences between the submitted version and the official published version of record.

People interested in the research are advised to contact the author for the final version of the publication, or visit the DOI to the publisher's website.

- The final author version and the galley proof are versions of the publication after peer review.

- The final published version features the final layout of the paper including the volume, issue and page numbers.

Link to publication

\footnotetext{
General rights rights.

- You may freely distribute the URL identifying the publication in the public portal. please follow below link for the End User Agreement:

www.umlib.nl/taverne-license

Take down policy

If you believe that this document breaches copyright please contact us at:

repository@maastrichtuniversity.nl

providing details and we will investigate your claim.
}

Copyright and moral rights for the publications made accessible in the public portal are retained by the authors and/or other copyright owners and it is a condition of accessing publications that users recognise and abide by the legal requirements associated with these

- Users may download and print one copy of any publication from the public portal for the purpose of private study or research.

- You may not further distribute the material or use it for any profit-making activity or commercial gain

If the publication is distributed under the terms of Article $25 \mathrm{fa}$ of the Dutch Copyright Act, indicated by the "Taverne" license above, 


\title{
Occupational exposure and amyotrophic lateral sclerosis in a prospective cohort
}

\author{
Tom Koeman, ${ }^{1}$ Pauline Slottje, ${ }_{1}^{1}$ Leo J Schouten, ${ }^{2}$ Susan Peters, ${ }^{1,3}$ Anke Huss, ${ }_{1}^{1}$ \\ Jan H Veldink, ${ }^{3}$ Hans Kromhout, ${ }^{1}$ Piet A van den Brandt, ${ }^{2}$ Roel Vermeulen ${ }^{1,4}$
}

- Additional material is published online only. To view please visit the journal online (http://dx.doi.org/10.1136/ oemed-2016-103780).

${ }^{1}$ Division of Environmental Epidemiology, Institute for Risk Assessment Sciences, Utrecht University, Utrecht,

The Netherlands

${ }^{2}$ Department of Epidemiology, GROW School for Oncology and Developmental Biology, Maastricht University Medical Centre, Maastricht, Netherlands ${ }^{3}$ Department of Neurology and Neurosurgery, Brain Center Rudolf Magnus, University Medical Center Utrecht, Utrecht, The Netherlands

${ }^{4}$ Julius Centre for Public Health Sciences and Primary Care, University Medical Center, Utrecht, The Netherlands

\section{Correspondence to}

Professor Roel Vermeulen, Institute for Risk Assessment Sciences, Division of

Environmental Epidemiology, Utrecht University: P.O. Box 80.178, 3584 TD, Utrecht, The Netherlands; r.c.h. vermeulen@uu.n

Received 4 September 2016 Revised 31 January 2017 Accepted 10 February 2017 Published Online First 29 March 2017

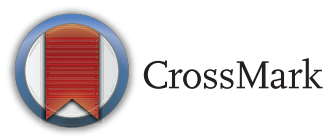

To cite: Koeman T, Slottje P, Schouten LJ, et al. Occup Environ Med 2017:74:578-585.

\section{ABSTRACT}

Objective To prospectively study suspected occupational risk factors for amyotrophic lateral sclerosis (ALS).

Methods For this case-cohort analysis within the prospective Netherlands Cohort Study, 58279 men and 62573 women aged 55-69 years at enrolment in 1986 were followed up for 17.3 years on ALS mortality. Information on occupational history and potential confounders were collected at baseline through a selfadministered questionnaire and entered for a random subcohort (2092 men and 2074 women) and ALS deaths (76 men and 60 women). Occupational exposure to solvents, pesticides, metals, extremely low frequency magnetic fields (ELF-MFs) and electrical shocks was estimated by means of job exposure matrices (JEMs). Associations between ever/never occupationally exposed and cumulative exposure and ALS mortality were analysed by gender using Cox regression.

Results Occupational exposure to ELF-MF showed a possible association with ALS mortality among men: HR for ever holding a job with high exposure versus background 2.19 (95\% (Cl): 1.02 to 4.73$)$ and HR for the highest tertile of cumulative exposure versus background 1.93 (95\% Cl 1.05 to 3.55).

Interpretation These results strengthen the evidence suggesting a positive association between ELF-MF exposure and ALS. We did not replicate earlier positive findings for other occupational exposures.

\section{INTRODUCTION}

Amyotrophic lateral sclerosis (ALS) is a progressive disease of the motor neuron system, usually resulting in death within 1-6 years of onset. ${ }^{1}$ Approximately 5\%-23\% of the cases of ALS are familial, suggesting that environmental exposures may play an important role in the occurrence of ALS. $^{2}$ A higher prevalence and an earlier onset of ALS has been observed in men compared with women. ${ }^{34}$ Educational level, ${ }^{15}$ smoking, ${ }^{6}$ physical activity, ${ }^{7}$ repeated physical trauma, ${ }^{8-10}$ and various occupational exposures ${ }^{11-13}$ have been postulated as risk factors for ALS. However, current evidence for these behavioural and environmental factors is still insufficient to draw strong conclusions about their relationship with ALS.

Occupational exposures that have been hypothesised to be related to ALS are extremely low frequency magnetic fields (ELF-MFs), electrical shocks, solvents, metals and pesticides. ${ }^{1}$ 11-14 Studies on these exposures suffered from one or more methodological shortcomings, such as
What this paper adds

- Multiple occupational exposures have been hypothesised to be related to amyotrophic lateral sclerosis (ALS), such as extremely low frequency magnetic fields (ELF-MFs), electrical shocks, solvents, metals and pesticides.

- Studies on these exposures suffered from one or more methodological shortcomings.

- This study, using The Netherlands Cohort Study, improves upon earlier efforts by using a large, prospective, general-population cohort, with complete job histories up to enrolment while testing for multiple occupational exposures.

- We observed an association between occupational exposure to ELF-MF and ALS mortality, but not with other occupational exposures.

analyses by occupation instead of assessing specific exposures, ${ }^{8}$ using self-reported exposures instead of more objective exposure measures, ${ }^{15}$ using only a single job instead of a full occupational history to assess exposure ${ }^{1316}$ and a limited ability to adjust for potential confounders. ${ }^{1617}$

We aimed to extend the current evidence base and improve on the previous studies by analysing the effects of occupational exposure to ELF-MF, electrical shocks, solvents, metals and pesticides on ALS mortality in a large, prospective, population-based cohort study ${ }^{18}$ with occupational history information up to baseline, using state-of-the-art job exposure matrices (JEMs) and detailed information on possible confounders.

\section{METHODS}

The Netherlands Cohort Study (NLCS) on diet and cancer consists of 58279 men and 62573 women who were enrolled in $1986 .{ }^{18}$ At the time of enrolment, subjects were 55-69 years old, lived throughout the Netherlands and completed a self-administered questionnaire on occupational history, dietary habits, lifestyle and other potential risk factors focusing on cancer. The cohort was followed up for cause-specific mortality and cancer incidence. Following a case-cohort approach, person-years were estimated using a randomly drawn subcohort (2411 men and 2589 women). Questionnaires were entered manually for incident cases as well as for the subcohort. Questionnaires 
Table 1 Distribution of age, level of education and occupational exposures previously hypothesised to be related to ALS by subcohort and casestatus

\begin{tabular}{|c|c|c|c|c|c|}
\hline \multirow[t]{2}{*}{ Exposure } & \multirow[t]{2}{*}{ Exposure level } & \multicolumn{2}{|l|}{$\begin{array}{l}\text { Subcohort } \\
n=4344\end{array}$} & \multicolumn{2}{|l|}{$\begin{array}{l}\text { Cases } \\
n=136\end{array}$} \\
\hline & & $\begin{array}{l}\text { Men } \\
\mathrm{n}=2092 \\
\mathrm{~N}(\%)\end{array}$ & $\begin{array}{l}\text { Women } \\
\mathrm{n}=2074 \\
\mathrm{~N}(\%)\end{array}$ & $\begin{array}{l}\text { Men } \\
n=76 \\
N(\%)\end{array}$ & $\begin{array}{l}\text { Women } \\
\mathrm{n}=60 \\
\mathrm{~N}(\%)\end{array}$ \\
\hline \multirow[t]{3}{*}{ Age category } & $55-59$ years & $766(37)$ & $774(37)$ & $23(30)$ & $15(25)$ \\
\hline & $60-64$ years & $734(35)$ & $697(34)$ & $27(36)$ & $22(37)$ \\
\hline & $65-69$ years & $592(28)$ & $603(29)$ & $26(34)$ & $23(38)$ \\
\hline \multirow[t]{4}{*}{ Level of education } & Lower vocational & $530(25)$ & $657(32)$ & $29(38)$ & $28(47)$ \\
\hline & Primary vocational & $433(21)$ & $469(23)$ & $15(20)$ & $11(18)$ \\
\hline & Secondary and medium vocational & $732(35)$ & $754(36)$ & $19(25)$ & $18(30)$ \\
\hline & Higher vocational & $397(19)$ & $194(9)$ & $13(17)$ & $3(5)$ \\
\hline \multirow[t]{4}{*}{ Physical activity } & $\leq 30 \mathrm{~min} /$ day & $387(18)$ & $509(25)$ & $14(18)$ & $16(27)$ \\
\hline & $>30-60 \mathrm{~min} /$ day & $648(31)$ & $653(31)$ & $22(29)$ & $23(38)$ \\
\hline & $>60-90 \mathrm{~min} /$ day & $394(19)$ & $470(23)$ & $16(21)$ & $10(17)$ \\
\hline & $>90 \mathrm{~min} /$ day & $663(32)$ & $442(21)$ & $24(32)$ & $11(18)$ \\
\hline \multirow[t]{4}{*}{ Body mass index } & Underweight & $14(1)$ & $30(1)$ & $0(0)$ & $2(3)$ \\
\hline & Normal weight & $1099(53)$ & $1116(54)$ & $48(63)$ & $33(55)$ \\
\hline & Overweight & $899(43)$ & $743(36)$ & $26(34)$ & $19(32)$ \\
\hline & Obese & $80(4)$ & $185(9)$ & $2(3)$ & $6(10)$ \\
\hline \multirow[t]{3}{*}{ Smoking } & Never smoked & $257(12)$ & $1194(58)$ & $8(11)$ & $38(63)$ \\
\hline & Former smoker & $1081(52)$ & $437(21)$ & $37(49)$ & $13(22)$ \\
\hline & Current smoker & $754(36)$ & $443(21)$ & $31(41)$ & $9(15)$ \\
\hline \multirow[t]{3}{*}{ ELF-MF* } & Background & $1009(48)$ & $1038(50)$ & $28(37)$ & $30(50)$ \\
\hline & Only ever low & $918(44)$ & $1021(49)$ & $39(51)$ & $29(48)$ \\
\hline & Ever high & $165(8)$ & $15(1)$ & $9(12)$ & $1(2)$ \\
\hline \multirow[t]{3}{*}{ Electric shockst } & Background & $1253(60)$ & $1948(94)$ & $41(54)$ & $57(95)$ \\
\hline & Only ever low & $322(15)$ & $119(6)$ & $17(22)$ & $3(5)$ \\
\hline & Ever high & $517(25)$ & $7(0)$ & $18(24)$ & $0(0)$ \\
\hline \multirow[t]{3}{*}{ Total solvents $\ddagger$} & Background & $1327(63)$ & $1697(82)$ & $46(61)$ & $50(83)$ \\
\hline & Only ever low & $424(20)$ & $343(17)$ & $13(17)$ & $9(15)$ \\
\hline & Ever high & $341(16)$ & $34(2)$ & $17(22)$ & $1(2)$ \\
\hline \multirow[t]{3}{*}{ Aromatic solventsł } & Background & $1422(68)$ & $1991(96)$ & $51(67)$ & $56(93)$ \\
\hline & Only ever low & $598(29)$ & $80(4)$ & $19(25)$ & $3(5)$ \\
\hline & Ever high & $72(3)$ & $3(0)$ & $6(8)$ & $1(2)$ \\
\hline \multirow[t]{3}{*}{ Chlorinated solvents $\ddagger$} & Background & $1585(76)$ & $1991(96)$ & $52(68)$ & $58(97)$ \\
\hline & Only ever low & $243(12)$ & $73(4)$ & $14(18)$ & $2(3)$ \\
\hline & Ever high & $264(13)$ & $10(0)$ & $10(13)$ & $0(0)$ \\
\hline \multirow[t]{3}{*}{ Metal exposure $\ddagger$} & Background & $1639(78)$ & $2063(99)$ & $56(74)$ & $59(98)$ \\
\hline & Only ever low & $189(9)$ & $9(0)$ & $8(11)$ & $0(0)$ \\
\hline & Ever high & $264(13)$ & $2(0)$ & $12(16)$ & $1(2)$ \\
\hline \multirow[t]{3}{*}{ Total pesticidesł } & Background & $1840(88)$ & $2029(98)$ & $69(91)$ & $57(95)$ \\
\hline & Only ever low & $86(4)$ & $13(1)$ & $4(5)$ & $1(2)$ \\
\hline & Ever high & $166(8)$ & $32(2)$ & $3(4)$ & $2(3)$ \\
\hline \multirow[t]{3}{*}{ Insecticides $\ddagger$} & Background & $1853(89)$ & $2032(98)$ & $70(92)$ & $57(95)$ \\
\hline & Only ever low & $75(4)$ & $10(0)$ & $3(4)$ & $1(2)$ \\
\hline & Ever high & $164(8)$ & $32(2)$ & $3(4)$ & $2(3)$ \\
\hline \multirow[t]{3}{*}{ Herbicides $\ddagger$} & Background & $1921(92)$ & $2040(98)$ & $73(96)$ & $58(97)$ \\
\hline & Only ever low & $78(4)$ & $29(1)$ & $2(3)$ & $2(3)$ \\
\hline & Ever high & $93(4)$ & $5(0)$ & $1(1)$ & $0(0)$ \\
\hline \multirow[t]{3}{*}{ Fungicidesł } & Background & $1884(90)$ & 2034 (98) & $70(92)$ & $58(97)$ \\
\hline & Only ever low & $81(4)$ & $29(1)$ & $4(5)$ & $2(3)$ \\
\hline & Ever high & $127(6)$ & $11(1)$ & $2(3)$ & $0(0)$ \\
\hline
\end{tabular}

*ELF-Job exposure matrix.

tElectrical Injury Job exposure matrix.

$\ddagger$ ALOHA+-Job exposure matrix.

ALS, amyotrophic lateral sclerosis; ELF-MF, extremely low frequency magnetic fields. 


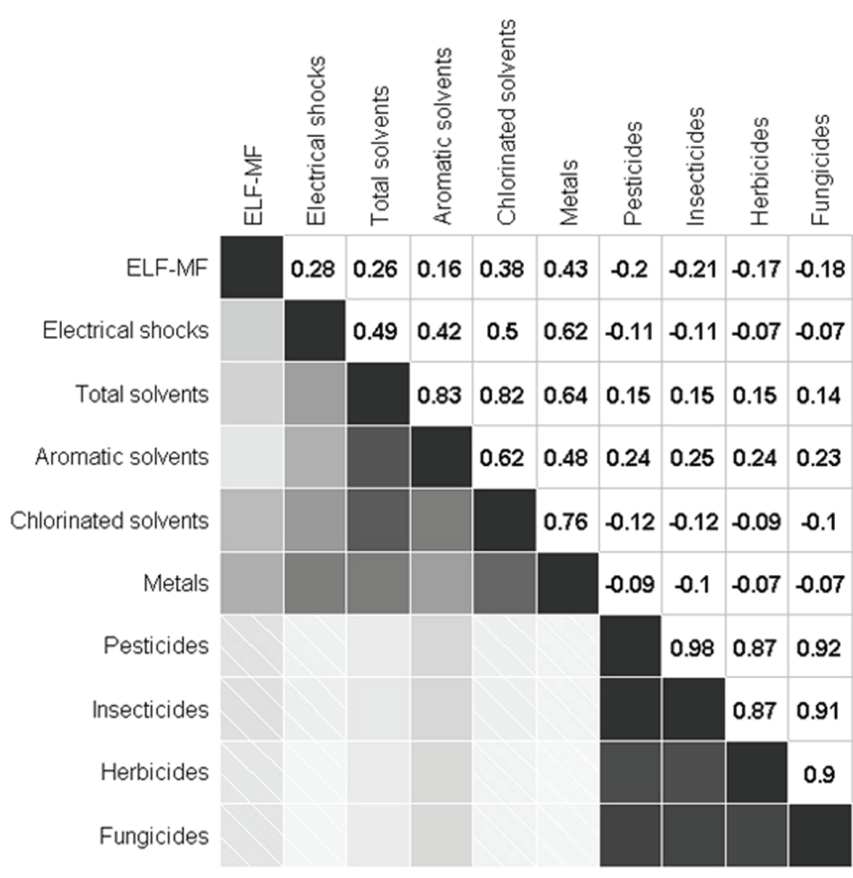

Figure 1 Correlogram displaying the Pearson correlations between cumulative occupational exposures among men in the subcohort. ELF-MF, extremely low frequency magnetic fields. Shaded: negative correlations; smooth: positive correlations; lighter coloring: lower correlation.

were entered blind to case/subcohort status by drawing extra (non-case) questionnaires at random, which were entered simultaneously with the new cases.

The NLCS was approved by the institutional review boards of the Netherlands Organisation for Applied Scientific Research TNO (Zeist) and Maastricht University (Maastricht).

\section{Follow-up and case definition}

Vital status for the period from January 1987 to October 2003 was obtained from the Dutch Bureau of Genealogy and the municipal resident registration. Causes of death were obtained from Statistics Netherlands, coded according to the 9th and 10th (since 1 January 1996) edition of the International Classification of Diseases, codes 335.20 and G12.2, respectively. For the current analyses, data were available for 17.3 years of follow-up (from September 1986 to December 2003). In total, 88 male and 70 female ALS deaths $(0.15 \%$ and $0.11 \%$ of entire cohort, respectively) were registered, either as a primary or secondary cause of death. Of these, seven men and two women were also part of the subcohort $(0.29 \%$ and $0.08 \%$ of the subcohort, respectively).

\section{Exposure assessment}

The baseline questionnaire contained questions on lifetime occupational history up to time of enrolment in the cohort (ie, when subjects were 55-65 years of age). Subjects reported whether they ever had a paid job, and if so they supplied the name of the company or institution they worked at, the type of company or institution, what was produced at their department, their job title, and period of employment for each job for up to five jobs.

Subjects in the subcohort who ever had paid jobs $(n=4344)$ reported 1.9 jobs on average. Jobs were coded by one designated researcher according to the Dutch occupational classification system developed in 1984 by Statistics Netherlands, based on the industry and occupational descriptions provided by the subjects.
These job codes were subsequently translated to the International Standard Classification of Occupations 1988 (ISCO-88) using a crosswalk described previously. ${ }^{19}$ Occupational exposures were assigned by linking the job histories to various JEMs by ISCO-88 job codes:

ELF-MF: using a recently developed ELF-JEM. ${ }^{20}$

Electrical shocks: using a recently developed Shock-JEM based on registries of occupational electric injuries. ${ }^{21}$

Total, aromatic and chlorinated solvents, metals, pesticides, insecticides, herbicides and fungicides: using the ALOHA+-JEM. ${ }^{19} 2223$

All these JEMs assign exposure based on intensity and probability of exposure, with the exception of the Shock-JEM, which is based on the probability of workplace electrical injuries. The JEMs were ordinal and had three exposure levels: no (or background), low and high exposure.

The following metrics of occupational exposure were used for each exposure: (1) Ever had a job with at maximum a high, a low or background occupational exposure (hereafter referred to as background, only low or ever high exposure respectively). If there were few exposed cases in a single category $(<5)$, the only low and ever high exposure categories were merged into one category, hereafter referred to as ever exposed. We also tested for trend based on the high, only low and background categories. (2) Cumulative exposure: calculated by first assigning weights to the exposure ratings reflecting the multiplicative nature of occupational exposure distributions (ie, no exposure: 0, low: 1, high: 4), then summing the products of the exposure weights and duration of each job over the entire job history. Subjects who had never had a paid job (eg, homemakers or other, $8 \%$ of cases and $6 \%$ of subcohort) were assigned background exposure in the main analyses. Subjects for whom all job information was missing ( $12 \%$ of cases and $12 \%$ of subcohort) were set to missing.

\section{Statistical analyses}

Associations between occupational exposures and ALS mortality were investigated using Cox proportional hazards models with age as the time scale, stratified by sex. Following the case-cohort approach, the number of cases was the number in the entire cohort, whereas the person-time was estimated through the follow-up of the members of the subcohort. 95\% CI were calculated using the robust estimator of variance to account for the additional variance introduced by the case-cohort. Censoring occurred at date of death, loss to follow-up or end of follow-up, whichever occurred first. Models were analysed using STATA V.12.1 (Statacorp, College Station, Texas, USA).

The following covariates were included in the risk models based on the literature ${ }^{1}$ : smoking (current vs former and non-smokers), attained level of education (primary vocational vs lower vocational, secondary and medium vocational and higher vocational), body mass index (in $\mathrm{kg} / \mathrm{m}^{2}$ ) and physical activity (in $\mathrm{min} /$ day). All these covariates were measured at baseline. Alcohol consumption in the year prior to baseline was also considered as a covariate, but as the evidence for an association with ALS is scarce and alcohol consumption showed no clear association with ALS mortality in the cohort, this confounder was not entered in the final models. Information on occupational history and potential confounders was available for analyses for 76 male and 60 female ALS cases and 2092 men and 2074 women in the subcohort.

The occupational exposure metrics were analysed as categorical variables, using background exposure as the reference category. For cumulative exposure, sex-specific tertiles in the subcohort were 
Table 2 Associations between ever/never occupationally exposed to selected agents and ALS mortality in men*

\begin{tabular}{|c|c|c|c|c|c|}
\hline & Exposure level & Cases & $\begin{array}{l}\text { Person-years in } \\
\text { subcohort }\end{array}$ & HR & $95 \% \mathrm{Cl}$ \\
\hline \multirow[t]{4}{*}{ Extremely low frequency magnetic fields } & Background & 28 & 13968 & 1.00 & Reference \\
\hline & Only ever low & 39 & 12979 & 1.57 & (0.4 to 2.63 ) \\
\hline & Ever high & 9 & 2185 & 2.19 & $(1,02$ to 4.73$)$ \\
\hline & Test for trend & 76 & 29132 & & $p=0.02$ \\
\hline \multirow[t]{4}{*}{ Electrical shocks } & No exposure & 41 & 17575 & 1.00 & Reference \\
\hline & Only ever low & 17 & 4423 & 1.47 & (0.80 to2.71) \\
\hline & Ever high & 18 & 7133 & 1.04 & (0.57 to 1.92$)$ \\
\hline & Test for trend & 76 & 29132 & & $p=0.73$ \\
\hline \multirow[t]{4}{*}{ Total solvents } & No exposure & 46 & 18547 & 1.00 & Reference \\
\hline & Only ever low & 13 & 5850 & 0.84 & (0.44 to 1.63$)$ \\
\hline & Ever high & 17 & 4734 & 1.46 & (0.81 to 2.61$)$ \\
\hline & Test for trend & 76 & 29132 & & $p=0.35$ \\
\hline \multirow[t]{4}{*}{ Aromatic solvents } & No exposure & 51 & 19902 & 1.00 & Reference \\
\hline & Only ever low & 19 & 8222 & 0.85 & (0.49 to 1.47 ) \\
\hline & Ever high & 6 & 1008 & 1.99 & (0.81 to 4.92$)$ \\
\hline & Test for trend & 76 & 29132 & & $p=0.59$ \\
\hline \multirow[t]{4}{*}{ Chlorinated solvents } & No exposure & 52 & 22211 & 1.00 & Reference \\
\hline & Only ever low & 14 & 3283 & 1.80 & (0.97 to 3.36$)$ \\
\hline & Ever high & 10 & 3640 & 1.23 & (0.63 to 2.39$)$ \\
\hline & Test for trend & 76 & 29132 & & $p=0.21$ \\
\hline \multirow[t]{4}{*}{ Metals } & No exposure & 56 & 22932 & 1.00 & Reference \\
\hline & Only ever low & 8 & 2541 & 1.25 & (0.57 to 2.75$)$ \\
\hline & Ever high & 12 & 3660 & 1.47 & (0.79 to 2.76 ) \\
\hline & Test for trend & 76 & 29132 & & $p=0.33$ \\
\hline \multirow[t]{2}{*}{ Pesticides } & No exposure & 69 & 25618 & 1.00 & Reference \\
\hline & Ever low or high & 7 & 3515 & 0.60 & (0.27 to 1.35$)$ \\
\hline \multirow[t]{2}{*}{ Insecticidest } & No exposure & 70 & 25762 & 1.00 & Reference \\
\hline & Ever low or high & 6 & 3371 & 0.54 & 0.23 to 1.26 \\
\hline \multirow[t]{2}{*}{ Herbicidest } & No exposure & 73 & 26738 & 1.00 & Reference \\
\hline & Ever low or high & 3 & 2395 & 0.36 & (0.11 to 1.18 ) \\
\hline \multirow[t]{2}{*}{ Fungicidest } & No exposure & 70 & 26243 & 1.00 & Reference \\
\hline & Ever low or high & 6 & 2890 & 0.62 & (0.26 to 1.47$)$ \\
\hline
\end{tabular}

*Cox proportional hazard regression using age as the time-axis, single occupational exposure adjusted for attained level of education.

tDue to the low number of exposed subjects, exposure categories were merged.

ALS, amyotrophic lateral sclerosis.

used to categorise the exposed individuals. A test for trend was performed based on the medians of the exposure categories.

We first analysed occupational exposures based on the ever/ never classification adjusting for attained educational level as a covariate. Depending on whether this analysis showed significant associations, or showed an increasing trend from background to ever high exposed, we further explored exposure-response associations using cumulative exposure. Lastly, if an occupational exposure showed a possible exposure-response association with ALS mortality in the analysis of cumulative exposure, we analysed this exposure while mutually adjusting for the other exposures.

\section{Sensitivity analyses}

Two types of sensitivity analyses were performed. First, all subjects with missing exposure levels due to a job history that contained too little information to be coded were assigned to

Table 3 Association between cumulative occupational ELF-MF exposure and ALS mortality in men*

\begin{tabular}{|c|c|c|c|c|c|}
\hline & Exposure level & Cases & Person-years in subcohort & HR & $95 \% \mathrm{Cl}$ \\
\hline \multirow[t]{5}{*}{ ELF-MF } & No exposure & 28 & 13968 & 1.00 & Reference \\
\hline & First tertile* & 12 & 5000 & 1.26 & 0.62 to 2.54 \\
\hline & Second tertile* & 16 & 4970 & 1.78 & 0.93 to 3.41 \\
\hline & Third tertile* & 20 & 5195 & 1.93 & 1.05 to 3.55 \\
\hline & Test for trend $t$ & 76 & 29133 & & $p=0.02$ \\
\hline
\end{tabular}

${ }^{*}$ Cox proportional hazard regression using age as the time-axis, single occupational exposure adjusted for attained level of education.

tContinuous scale.

ALS, amyotrophic lateral sclerosis; ELF-MF, extremely low frequency magnetic fields. 


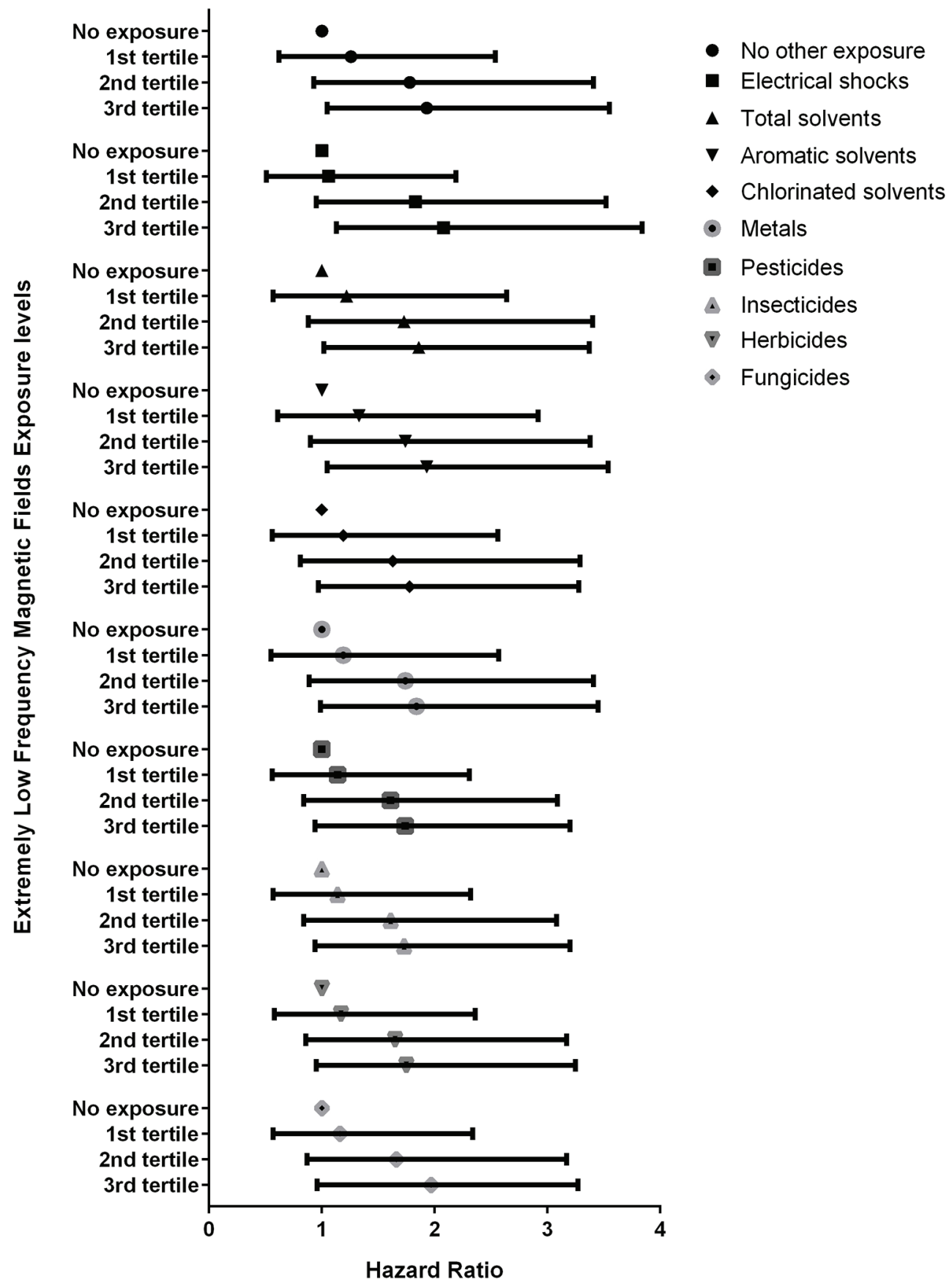

Figure 2 Associations between cumulative ELF-MF exposure and ALS mortality in men adjusted for other occupational exposure. ALS, amyotrophic lateral sclerosis; ELF-MF, extremely low frequency magnetic field.

the no/background exposure group instead of being omitted from the analyses. Second, an analysis was performed where subjects who never had a paid job at baseline, that is, homemakers and unemployed, were omitted from the analyses, whereas they were considered to be exposed to background levels in the main analysis.

\section{RESULTS}

Table 1 shows the exposure distribution of the selected potential confounders and occupational exposures for men and women in the subcohort and among ALS cases. Cases tended to have a lower level of attained education at baseline compared with the subjects in the subcohort. Forty-four per cent of cases ever had a blue collar job, compared with
$38 \%$ of the subcohort. Exposure prevalence in the subcohort varied across the different occupational exposures with ever high exposed varying between $2 \%$ to $25 \%$ for men and $0 \%$ to $2 \%$ for women (table 1 ). Due to the overall low number of exposed women, risk analyses for women were largely uninformative and limited to ever/never exposed analyses (see online supplementary figure e- 1 and table e-1). Here, we only present the results for men.

Correlation analyses between the different occupational exposures revealed low to highly correlated exposures. Two main exposure clusters could be identified. One cluster contains ELF-MF, electrical shocks, solvent and metal exposures. The other cluster contains exposure to pesticides, insecticides, herbicides and fungicides (see figure 1). 


\section{Single occupational exposure analyses}

In the ever/never exposure analysis (table 2), only ELF-MF showed a significant positive association with ALS mortality among men (adjusted HR (HR) ever high exposure versus background exposure: $2.19,95 \% \mathrm{CI} 1.02$ to 4.73$)$. The association also showed a significant test for trend $(p=0.02)$. Occupational exposure to solvents or metals also showed positive associations, but with wide CIs and without a clear trend. If the low and high exposure categories were merged, the results were comparable (see online Supplementary table e-1). In contrast, exposure to pesticides resulted in negative associations with ALS mortality. However, these analyses were limited by the low number of exposed cases resulting in wide CIs.

Based on the positive significant association in the ever/never analyses and sufficient exposed cases $(n>5)$ per cumulative exposure category, we analysed the possible association between cumulative exposure to ELF-MF and ALS mortality. The cumulative exposure analysis showed a significant positive association with cumulative ELF-MF exposure and ALS mortality with the third tertile versus background exposure resulting in a significant increased risk of 1.93 (95\% CI 1.05 to 3.55$)$ with a positive exposure-response trend across cumulative exposure categories $(\mathrm{p}=0.02)($ table 3$)$.

\section{Combined exposure analysis}

When analysed together with the other exposures, HRs for the third tertile of cumulative exposure to ELF-MF among men changed from 1.93 (95\% CI 1.05 to 3.55) in the single cumulative occupational exposure analysis to 1.73 (95\% CI 0.94 to 3.20) when analysed together with insecticides and 2.09 (95\% CI 1.13 3.84) when analysed together with electrical shocks (see figure 2). In these analyses, none of the other occupational exposures was significantly associated with ALS mortality (results not shown).

\section{Sensitivity analyses}

The sensitivity analyses omitting subjects never having a paid job or assigning subjects without detailed occupational exposure to background exposure levels showed only minor changes to the risk estimates obtained in the main analysis and did not result in different conclusions (results not shown).

\section{DISCUSSION}

We studied occupational exposures with an a priori hypothesis of being related to an increased ALS risk. Of the 10 selected exposures, only ELF-MF showed a significant and increasing exposure-dependent association with ALS mortality.

\section{Electromagnetic fields and shocks}

Previous studies have suggested that so-called electrical occupations are associated with an increased risk of ALS. ${ }^{8152425}$ Both exposure to ELF-MF and electrical shocks have been proposed as an explanation for this finding. ${ }^{826}$ However, studies assessing occupational exposure to ELF-MF across occupations have been less consistent than those of electric occupations, with some showing a positive association ${ }^{17}{ }^{24-31}$ while others did not. ${ }^{16} 25$ 32-34 Industrial cohort studies using more detailed job histories more frequently reported positive associations, ${ }^{17} 2930$ whereas general population studies using the job reported on the death certificate ${ }^{16}$ or jobs at single time points more often reported no associations. ${ }^{25} 32$

Only few studies have assessed the association of ALS mortality and self-reported electrical shocks. ${ }^{8}{ }^{15}$ Deapen and Henderson ${ }^{8}$ reported increased risks between self-reported electrical shocks producing unconsciousness and ALS incidence. Gunnarson et $a l^{15}$ found no association between self-reported high-voltage electrical shocks and ALS incidence, although the authors did report an association for ALS with low-voltage electrical shocks in a subgroup aged 45-59 years. Recently, some attempts have been made to assess these associations using JEMs. ${ }^{31} 33{ }^{34}$ Of these studies, only Fischer $e t a l^{34}$ provided weak support for an association between occupational exposure to electrical shocks and an increased incidence of ALS. We found no indications for an increased risk of ALS for subjects with a higher risk of injuries due to electrical shocks in the workplace. In contrast, we did observe an exposure-dependent association between ELF-MF exposure and ALS mortality. This would suggest that exposure to ELF-MF rather than electric shocks in electric occupations may drive the observed increased risk of ALS.

\section{Solvents}

Exposure to solvents as an overall category has been implicated as a possible risk factor for ALS in earlier epidemiological studies, ${ }^{815}$ but results have been heterogeneous. ${ }^{356}$ Some studies looking at more specific solvents such as chlorinated solvents, glycol ethers ${ }^{37}$ and formaldehyde ${ }^{38}{ }^{39}$ have shown positive associations, although these results have not been replicated. ${ }^{12} 39$ We found no significant association between occupational exposure to total solvents, chlorinated, or aromatic solvents and ALS mortality. Our study therefore does not support previous findings of an association between occupational solvent exposure, including aromatic and chlorinated solvents and ALS mortality.

\section{Metals}

Occupational exposure to lead and mercury has been associated with ALS in previous studies. ${ }^{12}{ }^{40}$ Some studies have also associated increased levels of lead in plasma with ALS, although other metals have not shown similarly consistent associations. ${ }^{41}{ }^{42}$ Assignment of specific metals based on a JEM is difficult, as occupational categories are generally too broad to distinguish between exposures to specific metals. Some studies have found an association between occupational exposure to metals and ALS mortality using this methodology, ${ }^{36}$ although others did not. ${ }^{43}$ We used the ALOHA+-JEM to assign total metal exposure, which due to the broad categorisation might not have captured possible associations between specific metals and ALS mortality. While our analyses showed increased HRs for exposure to metals, none were significant. Our study therefore provides little further evidence for an association between occupational exposure to metals and ALS mortality. However, the prevalence of exposure was low. Together with the inability to estimate potential risks associated with exposure to specific metals, we cannot exclude small risks related to specific metals.

\section{Pesticides}

Working in agricultural jobs has been indicated as a risk factor for ALS. ${ }^{12}$ Three meta-analyses on pesticide exposures and risk of ALS concluded that occupational exposure to pesticides increases the risk of ALS in men. ${ }^{11}{ }^{144}$ Studies included in these meta-analyses generally did not make a distinction between the types of pesticides used precluding the identification of specific pesticides related to ALS risk. A subsequent study, conducted after the meta-analyses, showed no elevated risk of ALS mortality and exposure to pesticides but did show increased risks for several specific pesticides, including exposure to aldrin and dieldrin. ${ }^{14}$ Malek $e t a l^{36}$ and Yu $e t a l^{43}$ also showed an association 
between occupational exposure to pesticides and ALS incidence. We found a non-significant, negative association between occupational exposure to pesticides, herbicides or insecticides and ALS mortality. These negative associations were unexpected and offer no further support for an association between occupational exposure to pesticides and ALS within the general population. Due to the low number of exposed cases in the cohort, we had to collapse the high and low exposure categories. Therefore, we also could not investigate possible exposure-response relationships.

\section{Combined exposure analyses}

Cumulative occupational exposures to ELF-MF, shocks, solvents and metals showed moderate to high correlations. These correlations are mainly driven by jobs in the metal industry and by metal workers in construction industries. In our combined exposure analysis of ELF-MF adjusted for other occupational exposures in bivariate models, the patterns observed for ELF-MF remained the same, increasing our confidence in the results.

\section{Strengths and limitations}

Our study has several strengths compared with earlier studies. First, we used a prospective cohort to investigate the effects of occupational exposures on ALS mortality. The majority of studies on the association between occupational exposure to chemical agents and ALS have been performed in case-control settings, ${ }^{12}$ which may be vulnerable to recall bias. Second, we used JEMs to assess exposure levels instead of relying on self-reported exposure. Subjects may overestimate their own past exposures, leading to exposure misclassification and possibly bias if differential by case status. ${ }^{45}$ Third, we used a cohort with extensive information on potential confounders. This allowed us to address potential confounding both by demographic and lifestyle factors. Lastly, the NLCS includes information for up to five jobs up to baseline, instead of using a single occupation, which has been the case in many of the general population studies on ELF-MF and ALS to date. ${ }^{16}$ Given the age of the subjects at baseline and the average number of jobs reported at baseline (2.1 for men and 1.6 for women), we covered most of the job history for all subjects.

However, our study also had a number of limitations. First, we used causes of death to identify cases of ALS mortality, rather than using ALS incidence. Although the progression of ALS is generally fast, with patients dying on average 1-6 years after diagnosis, ${ }^{1}$ the cause of death could be misclassified on the death certificate. ${ }^{4647}$ We also used the ICD-10 code for motor neuron disease (ICD-10 12.2) to identify ALS. Although ALS forms the large majority of motor neuron disease cases, these are not synonymous. In the NLCS, we observed a crude mortality rate of nine ALS mortality cases per 100000 person-years, which is in line with estimates of the incidence rates in The Netherlands for this age group ( $~ 8$ per 100000 person-years for people 65-69 years of age). ${ }^{48}$ This provides evidence that our study has no significant under ascertainment of ALS cases through the mortality registration. Furthermore, it is unlikely that any under ascertainment or disease misclassification is differential by occupational exposure. As such, it would, if present, result in a loss of power without biasing the results.

Second, information on the occupational history of the subjects was only available up to baseline. However, as the population was between 55 and 70 years of age a large proportion of the cohort had already retired at baseline $(79 \%$ of cases and $78 \%$ of the subcohort). Furthermore, on average, subjects in the cohort retired at 62 years of age, indicating that these subjects would only add a small number of exposed years to the cumulative exposure in the subcohort and cases. Therefore, this is unlikely to have a major influence on the results. Third, while the use of JEMs to assign occupational exposures is not prone to misclassification due to recall bias of self-reported exposure, it is possibly less reliable for some (specific) exposures when compared with expert assessment. ${ }^{45}$ Expert assessment was not possible as no detailed information on the job (eg, tasks performed) was available within the cohort. Furthermore, the JEMs used broad categories of occupational exposures (eg, metals, solvents and insecticides). This might have led to missing associations with specific occupational exposures, such as lead, ${ }^{15}$ formaldehydes ${ }^{38}$ or organochlorine insecticides. ${ }^{14}$ As the Shock-JEM is based on accident data, associations with shocks that did not lead to severe consequences might have been missed as well.

Finally, while the NLCS cohort is large, ALS is a rare disease, and the low numbers of high exposed subjects led to low power to detect potential effects of occupational exposures on ALS, in particular among women.

\section{CONCLUSIONS}

We studied the association between selected occupational exposures and ALS mortality. Only for ELF-MF in men we observed a significant increased risk of ALS mortality with increasing exposure levels. The other occupational exposures showed some weak non-significant associations with ALS mortality among men and women, without showing clear exposure-dependent trends in risk. This prospective study offers further support for an association between occupational exposure to ELF-MF and an increased risk of ALS mortality.

Funding This work was supported by The Netherlands Organization for Health Research (ZonMW) within the programme Electromagnetic Fields and Health Research under grant numbers 85200001 and 85800001 .

Competing interests None declared.

Provenance and peer review Not commissioned; externally peer reviewed.

(c) Article author(s) (or their employer(s) unless otherwise stated in the text of the article) 2017. All rights reserved. No commercial use is permitted unless otherwise expressly granted.

\section{REFERENCES}

1 Ahmed A, Wicklund MP. Amyotrophic lateral sclerosis: what role does environment play? Neurol Clin 2011:29:689-711.

2 Andersen PM, Al-Chalabi A. Clinical genetics of amyotrophic lateral sclerosis: what do we really know? Nat Rev Neuro/ 2011;7:603-15.

3 McCombe PA, Henderson RD. Effects of gender in amyotrophic lateral sclerosis. Gend Med 2010;7:557-70.

4 Chiò A, Logroscino G, Hardiman 0, et al. Prognostic factors in ALS: a critical review. Amyotroph Lateral Scler 2009;10:310-23.

5 Sutedja NA, Veldink JH, Fischer K, et al. Lifetime occupation, education, smoking, and risk of ALS. Neurology 2007;69:1508-14.

6 Gallo V, Bueno-De-Mesquita HB, Vermeulen R, et al. Smoking and risk for amyotrophic lateral sclerosis: analysis of the EPIC cohort. Ann Neurol 2009;65:378-85.

7 Beghi E, Logroscino G, Chiò A, et al. Amyotrophic lateral sclerosis, physical exercise, trauma and sports: results of a population-based pilot case-control study. Amyotroph Lateral Scler 2010;11:289-92.

8 Deapen DM, Henderson BE. A case-control study of amyotrophic lateral sclerosis. Am J Epidemiol 1986;123:790-9.

9 Peters TL, Fang F, Weibull CE, et al. Severe head injury and amyotrophic lateral sclerosis. Amyotroph Lateral Scler Frontotemporal Degener 2013;14:267-72.

10 Chiò A, Benzi G, Dossena M, et al. Severely increased risk of amyotrophic lateral sclerosis among Italian professional football players. Brain 2005;128:472-6.

11 Malek AM, Barchowsky A, Bowser R, et al. Pesticide exposure as a risk factor for amyotrophic lateral sclerosis: a meta-analysis of epidemiological studies: pesticide exposure as a risk factor for ALS. Environ Res 2012;117:112-9.

12 Sutedja NA, Veldink JH, Fischer K, et al. Exposure to chemicals and metals and risk of amyotrophic lateral sclerosis: a systematic review. Amyotroph Latera/ Scler 2009;10:302-9. 
13 Vergara X, Kheifets L, Greenland S, et al. Occupational exposure to extremely lowfrequency magnetic fields and neurodegenerative disease: a meta-analysis. J Occup Environ Med 2013;55:135-46.

14 Kamel F, Umbach DM, Bedlack RS, et al. Pesticide exposure and amyotrophic lateral sclerosis. Neurotoxicology 2012;33:457-62.

15 Gunnarsson LG, Bodin L, Söderfeldt B, et al. A case-control study of motor neurone disease: its relation to heritability, and occupational exposures, particularly to solvents. Br J Ind Med 1992:49:791-8.

16 Savitz DA, Loomis DP, Tse CK. Electrical occupations and neurodegenerative disease: analysis of U.S. mortality data. Arch Environ Health 1998;53:71-4.

17 Röösli M, Lörtscher M, Egger M, et al. Mortality from neurodegenerative disease and exposure to extremely low-frequency magnetic fields: 31 years of observations on Swiss railway employees. Neuroepidemiology 2007;28:197-206.

18 van den Brandt PA, Goldbohm RA, van 't Veer P, et al. A large-scale prospective cohort study on diet and cancer in The Netherlands. J Clin Epidemio/ 1990;43:285-95.

19 Koeman T, Offermans NS, Christopher-de Vries Y, et al. JEMs and incompatible occupational coding systems: effect of manual and automatic recoding of job codes on exposure assignment. Ann Occup Hyg 2013;57:107-14.

20 Koeman T, Slottje P, Kromhout H, et al. Occupational exposure to extremely lowfrequency magnetic fields and cardiovascular disease mortality in a prospective cohort study. Occup Environ Med 2013;70:402-7.

21 Huss A, Vermeulen R, Bowman JD, et al. Electric shocks at work in Europe: development of a job exposure matrix. Occup Environ Med 2013;70:261-7.

22 de Vocht F, Zock JP, Kromhout H, et al. Comparison of self-reported occupational exposure with a job exposure matrix in an international community-based study on asthma. Am J Ind Med 2005:47:434-42.

23 Matheson MC, Benke G, Raven J, et al. Biological dust exposure in the workplace is a risk factor for chronic obstructive pulmonary disease. Thorax 2005;60:645-51.

24 Savitz DA, Checkoway H, Loomis DP. Magnetic field exposure and neurodegenerative disease mortality among electric utility workers. Epidemiology 1998;9:398-404.

25 Feychting $\mathrm{M}$, Jonsson F, Pedersen NL, et al. Occupational magnetic field exposure and neurodegenerative disease. Epidemiology 2003;14:413-19.

26 Farrell DF, Starr A. Delayed neurological sequelae of electrical injuries. Neurology 1968;18:601-6.

27 Davanipour Z, Sobel E, Bowman JD, et al. Amyotrophic lateral sclerosis and occupational exposure to electromagnetic fields. Bioelectromagnetics 1997;18:28-35.

28 Håkansson N, Gustavsson P, Johansen C, et al. Neurodegenerative diseases in welders and other workers exposed to high levels of magnetic fields. Epidemiology 2003; 14:420-6.

29 Johansen C, Olsen JH. Mortality from amyotrophic lateral sclerosis, other chronic disorders, and electric shocks among utility workers. Am J Epidemiol 1998:148:362-8.

30 Sorahan T, Kheifets L. Mortality from Alzheimer's, motor neuron and Parkinson's disease in relation to magnetic field exposure: findings from the study of UK electricity generation and transmission workers, 1973-2004. Occup Environ Med 2007:64:820-6.
31 Huss A, Spoerri A, Egger M, et al. Occupational exposure to magnetic fields and electric shocks and risk of ALS: the Swiss National Cohort. Amyotroph Lateral Scler Frontotemporal Degener 2015;16:80-5

32 Parlett LE, Bowman JD, van Wijngaarden E. Evaluation of occupational exposure to magnetic fields and motor neuron disease mortality in a population-based cohort. J Occup Environ Med 2011;53:1447-51.

33 Vergara XP, Fischer HJ, Yost M, et al. Job exposure matrix for electric shock risks with their uncertainties. Int I Environ Res Public Health 2015;12:3889-902.

34 Fischer HJ, Vergara XP, Yost M, et al. Developing a job-exposure matrix with exposure uncertainty from expert elicitation and data modeling. J Expo Sci Environ Epidemiol 2017:27.

35 McGuire V, Longstreth WT, Nelson LM, et al. Occupational exposures and amyotrophic lateral sclerosis. A population-based case-control study. Am J Epidemiol 1997; 145:1076-88.

36 Malek AM, Barchowsky A, Bowser R, et al. Environmental and occupational risk factors for amyotrophic lateral sclerosis: a case-control study. Neurodegener Dis 2014:14:31-8

37 Fang F, Quinlan P, Ye W, et al. Workplace exposures and the risk of amyotrophic latera sclerosis. Environ Health Perspect 2009;117:1387-92.

38 Weisskopf MG, Morozova N, O'Reilly EJ, et al. Prospective study of chemical exposures and amyotrophic lateral sclerosis. J Neurol Neurosurg Psychiatry 2009;80:558-61.

39 Peters TL, Kamel F, Lundholm C, et al. Occupational exposures and the risk of amyotrophic lateral sclerosis. Occup Environ Med 2017;74:87-92.

40 Wang MD, Gomes J, Cashman NR, et al. A meta-analysis of observational studies of the association between chronic occupational exposure to lead and amyotrophic lateral sclerosis. J Occup Environ Med 2014;56:1235-42.

41 Bocca B, Forte G, Oggiano R, et al. Level of neurotoxic metals in amyotrophic latera sclerosis: a population-based case-control study. J Neurol Sci 2015;359:11-17.

42 Garzillo EM, Lamberti M, Genovese G, et al. Blood lead, manganese, and aluminum levels in a regional Italian cohort of ALS patients: does aluminum have an influence? J Occup Environ Med 2014;56:1062-6.

43 Yu Y, Su FC, Callaghan BC, et al. Environmental risk factors and amyotrophic lateral sclerosis (ALS): a case-control study of ALS in Michigan. PLoS One 2014:9:e101186.

44 Kang H, Cha ES, Choi GJ, et al. Amyotrophic lateral sclerosis and agricultural environments: a systematic review. J Korean Med Sci 2014;29:1610-7.

45 Tielemans E, Heederik D, Burdorf A, et al. Assessment of occupational exposures in a general population: comparison of different methods. Occup Environ Med 1999;56:145-51.

46 Kamel F, Umbach DM, Stallone L, et al. Association of lead exposure with survival in amyotrophic lateral sclerosis. Environ Health Perspect 2008;116:943-7.

47 Stickler DE, Royer JA, Hardin JW. Accuracy and usefulness of ICD-10 death certificate coding for the identification of patients with ALS: results from the South Carolina ALS surveillance pilot project. Amyotroph Lateral Scler 2012;13:69-73.

48 Huisman $\mathrm{MH}$, de Jong SW, van Doormaal PT, et al. Population based epidemiology of amyotrophic lateral sclerosis using capture-recapture methodology. J Neurol Neurosurg Psychiatry 2011;82:1165-70. 